\title{
Perceptions of and attitudes to alcohol use among Pakistani medical students
}

\author{
Nazish Imran MRCPsych, ${ }^{1}$ Imran ljaz Haider MRCPsych DPM, ${ }^{2}$ Atif Sohail MBBS, ${ }^{3}$ \\ Mohsan Zafar MBBS ${ }^{4}$ and Muhammad Riaz Bhatti FRCPsych DPM ${ }^{5}$
}

\begin{abstract}
${ }^{1}$ Assistant Professor, Child and Family Psychiatry Department, King Edward Medical University, Lahore, Pakistan, email nazishimran@hotmail.com; ${ }^{2}$ Associate Professor, Department of Psychiatry and Behavioural Sciences, Fatima Memorial College of Medicine and Dentistry, Lahore; ${ }^{3}$ House Officer, Child and Family Psychiatry Department, King Edward Medical University, Lahore; ${ }^{4}$ Resident Medical Officer, Department of Psychiatry and Behavioural Sciences, Fatima Memorial College of Medicine and Dentistry, Lahore; ${ }^{5}$ Professor, Department of Psychiatry and Behavioural Sciences, King Edward Medical University, Lahore
\end{abstract}

\begin{abstract}
tudies worldwide have reported alarming rates of alcohol misuse among medical students (Webb et al, 1996; Kuo et al, 2002; Akvadar et al, 2004). These reports are surprising as well as of extreme concern, as medical professionals are supposedly more educated on the harmful effects of excessive alcohol consumption. The majority of studies exploring the knowledge and attitudes of medical students regarding alcohol have been from the USA and the UK, with only few from lower-income countries and the Islamic world (Kumar \& Basu, 2000; Akvadar et al, 2004).

Medical students' perceptions of alcohol use may be determined by various factors, including cultural, societal and religious background. Pakistan is an Islamic state, and alcohol use is religiously and legally forbidden; nevertheless, alcohol use is seen as socially acceptable in some sections of Pakistani society. As alcohol is a taboo issue and addiction medicine is not an integral part of the undergraduate curriculum in Pakistan, it may be plausible that Pakistani medical students knowledge of alcohol use is overestimated. Knowledge is said to influence attitudes and behaviour, so we aimed to assess the knowledge and attitudes regarding alcohol of medical undergraduates in the city of Lahore in Pakistan.
\end{abstract}

\section{Method}

This was a cross-sectional study, approved by the ethical review board of the King Edward Medical University. Informed consent was obtained from all the participants (undergraduate students at a public and a private medical university in Lahore). A structured questionnaire based on a literature review in this area was constructed by the research team in the English language. It was piloted on 20 students and then modified to address identified deficiencies.

The first part of the questionnaire sought demographic information. The second part covered the perceptions of medical students regarding alcohol. These included predisposing and risk factors for alcohol misuse, factors protecting against it and beliefs regarding the adverse and beneficial effects of alcohol. Their views on possible solutions to alcohol misuse among medical students were also sought. Participants were also briefly asked about their own practice regarding use of substances, including alcohol. All possible measures were taken to ensure confidentiality.
The questionnaire was distributed and then collected by the data-collection team. Data were analysed using SPSS 10.0 software. The chi-squared test was used to examine associations between perceptions and various variables. For all purposes, a $P$ value of $<0.05$ was considered significant.

\section{Results}

Out of 1500 questionnaires distributed, 1299 filled questionnaires were received (response rate of $86.6 \%) ; 1024$ (78.8\%) were from students at the public medical university and 275 (21.2\%) from students at the private medical college. There were 457 males and 842 females. Almost half the respondents were in the age group 18-20.

Twenty-one per cent of respondents believed daily alcohol intake constituted a serious problem, while 38\% believed even once in a lifetime use represented a serious problem.

When asked about what would predispose students to take alcohol, consumption of alcohol by friends was the most commonly identified factor (Table 1). Gender differences were observed, with more girls perceiving use of alcohol by friends as a significant predisposing factor than boys $(P<0.001)$. Curiosity and academic stress were the most commonly reported reasons for students taking up alcohol; religion and moral unacceptability were identified as protective factors (Table 1).

Ten per cent of respondents said that alcohol improved academic performance by improving mood and concentration, while $38 \%$ felt it helped to alleviate stress. Males were more likely to believe in a positive association between use of alcohol and improvement in academic performance $(P<0.001)$.

About half of the respondents resided in hostels - residential complexes managed by medical colleges in the vicinity of teaching hospitals for their students and doctors (in particular those from remote areas), and a large majority of respondents felt that students living in hostels were predisposed to using alcohol, the top reasons being lack of parental influence (55\%), easier access to alcohol (40\%), greater stress $(23 \%)$ and greater peer pressure (18\%).

Counselling $(48 \%)$, more recreational facilities on campus (42\%), frequent checks by security staff in hostels (35\%) and rehabilitation programmes (26\%) were the leading suggestions to reduce the problem of alcohol use on campus. 
Table 1 Factors related to alcohol misuse by medical students

\begin{tabular}{|c|c|c|}
\hline & \multicolumn{2}{|c|}{$\begin{array}{l}\text { Respondents answering } \\
\text { in affirmative, } n(\%)\end{array}$} \\
\hline $\begin{array}{l}\text { Predisposing factors } \\
\text { Consumption of alcohol by friends } \\
\text { Consumption of alcohol by family } \\
\text { Tobacco smoking }\end{array}$ & $\begin{array}{r}1096 \\
281 \\
289\end{array}$ & $\begin{array}{l}(84.4) \\
(21.7) \\
(22.3)\end{array}$ \\
\hline $\begin{array}{l}\text { Reasons for students taking alcohol } \\
\text { Curiosity (experimentation) } \\
\text { Academic stress } \\
\text { Peer pressure } \\
\text { To feel good (get high) } \\
\text { To help with sleep } \\
\text { Other }\end{array}$ & $\begin{array}{r}619 \\
589 \\
388 \\
301 \\
190 \\
48\end{array}$ & $\begin{array}{r}(47.7) \\
(45.4) \\
(29.9) \\
(23.2) \\
(14.7) \\
(3.8)\end{array}$ \\
\hline $\begin{array}{l}\text { Protective factors } \\
\text { Religion } \\
\text { Moral unacceptability } \\
\text { Side-effects/risks } \\
\text { Fear of being caught } \\
\text { Other }\end{array}$ & $\begin{array}{r}569 \\
554 \\
352 \\
274 \\
50\end{array}$ & $\begin{array}{r}(57.1) \\
(55.6) \\
(35.3) \\
(27.5) \\
(3.9)\end{array}$ \\
\hline $\begin{array}{l}\text { Perceived adverse effects } \\
\text { Addiction } \\
\text { Threats to one's own and others' lives } \\
\text { Socially inappropriate behaviour } \\
\text { Psychological complications } \\
\text { Physical complications } \\
\text { Decreased academic performance }\end{array}$ & $\begin{array}{l}813 \\
545 \\
476 \\
452 \\
366 \\
305\end{array}$ & $\begin{array}{l}(63.0) \\
(42.0) \\
(36.7) \\
(34.8) \\
(28.2) \\
(23.5)\end{array}$ \\
\hline
\end{tabular}

Comparisons of the perceptions of the medical students at the public and private institutions (using the chi-squared test) did not reveal any statistically significant results.

Seventeen per cent of respondents (222) admitted to ever experimenting with cigarettes, alcohol or drugs, with $3.6 \%$ admitting to use of one or more of these substances at the time of the study. Among these 222 students, alcohol use was reported by 58 students $(26.2 \%)$, second only to cigarettes $(175 ; 78.9 \%)$. Students belonging to the private medical college were more likely to have experimented with alcohol $(P<0.001)$.

\section{Discussion}

Our study provides further evidence of gaps in the knowledge of alcohol among medical students in Pakistan. This is a matter of concern because medical students, as future physicians, will be treating patients with alcohol-related problems. Many were unaware of potential adverse effects of alcohol misuse and on the contrary considered alcohol to be helpful in stress alleviation. In Pakistan, alcohol and drugs are not discussed openly, for societal, cultural and religious reasons. Medical school can therefore be considered critical in providing future physicians with a sound knowledge of the adverse effects of alcohol misuse. Unfortunately, the undergraduate curriculum in addiction medicine in Pakistan is inadequate in this respect. It may be because of the perception that the Muslim medical community is immune to problems of alcohol and drug misuse, due to religious factors. This may be coupled with the mistaken belief that medical students are already fully aware of the harmful effects of these substances.

Factors commonly identified by our respondents as predisposing medical students to use alcohol - such as peer involvement and living away from home - have been well established by previous research (Naskar \& Bhattacharya,
1999; Gjeruldsen et al, 2003). The most fequently endorsed reasons for students misusing alcohol were curiosity (47.7\%), academic stress (45.4\%) and peer pressure (29.9\%). Previous studies done in Pakistan and Nigeria have cited peer pressure, curiosity, academic stress, euphoria, family conflicts and mental health problems as common reasons for students misusing alcohol and drugs (Gjeruldsen et al, 2003; Shafiq et al, 2006). These factors include the pressure felt by students to excel in their studies, the expectations of families and the wish to join in peer groups and associated activities, even when considered harmful. A conscious effort needs to be made to alleviate such pressures.

Another interesting finding was that students believed that using alcohol is a way to look cool and fashionable. This, together with curiosity about new and adventurous pursuits, may lead students to experiment with alcohol and other illicit drugs.

Given the sensitivity of the issue, students' own behaviour regarding substance use was not explored in detail. However, the frequency and pattern of psychoactive substance misuse among our respondents is in line with the social acceptability of cigarette smoking in Pakistani society, especially among young people. However, the significant number of respondents who had experimented with alcohol negates the perception of alcohol not being a major problem among Pakistani medical students.

Our study's strengths include large sample size and good response rate. Limitations include the restricted generalisability of the results and possible differences between students' actual perceptions and how they answered the questionnaire.

We conclude that undergraduate medical students in Pakistan are inadequately aware of the potential hazards of alcohol misuse. The relevant risk factors as well as protective factors for alcohol use in medical students need to be identified in nationwide studies. Our study also underscores the need for integration of addiction medicine in the undergraduate curriculum. Efforts should be made at the secondary school and college level to increase awareness of the dangers of substance misuse and to make students realise that experimental use of drugs may lead to misuse and dependence.

\section{References}

Akvadar, Y., Demiral, Y., Ergor, G., et al (2004) Substance use among medical students and physicians in a medical school in Turkey. Social Psychiatry and Psychiatric Epidemiology, 39, 502-506.

Gjeruldsen, S., Myrvang, B. \& Opjordsmoen, S. (2003) Risk factors for drug addiction and its outcome. A follow-up study over 25 years. Nordic Journal of Psychiatry, 57, 373-376.

Kumar, P. \& Basu, D. (2000) Substance abuse by medical students and doctors. Journal of the Indian Medical Association, 98, 447-452.

Kuo, M., Adlaf, E. M., Lee, H., et al (2002) More Canadian students drink but American students drink more: comparing college alcohol use in two countries. Addiction, 97, 1583-1592.

Naskar, N. N. \& Bhattacharya, S. K. (1999) A study on drug abuse among the undergraduate medical students in Calcutta. Journal of the Indian Medical Association, 97, 20-21.

Shafiq, M., Shah, Z., Saleem, A., et al (2006) Perceptions of Pakistani medical students about drugs and alcohol. Substance Abuse Treatment, Prevention and Policy, 1, 31.

Webb, E., Ashton, C. H., Kelly, P., et al (1996) Alcohol and drug use in UK university students. Lancet, 48, 922-925. 